\title{
CORRESPONDENCIA PEDRO SAINZ RODRÍGUEZ Y GREGORIO MARAÑÓN POSADILLO
}

\section{Correspondence between Pedro Sainz Rodríguez and} Gregorio Marañón Posadillo

\author{
JULIO ESCRIBANO HERNÁNDEZ \\ Fundación Universitaria Española \\ julio.escribano@hotmail.es \\ ORCID ID: 0000-0001-5076-7291
}

Recibido: 14-09-2021 / Aceptado: 05-10-2021 DOI: https://doi.org/10.51743/cilh.vi47.241

RESUMEN

El artículo expone este estudio la amistad entre el Dr. Marañón y el insigne académico Sainz Rodríguez, iniciada en 1924 a través de una correspondencia, interrumpida por la opción política y la conversación telefónica. Sin embargo, crece a partir de 1955 al intercambiar inquietudes intelectuales, y por último finaliza con la muerte de Marañón en la primavera de 1960.

PALABRAS CLAVE: correspondencia; república; monarquía; Sainz Rodríguez;

Gregorio Marañón.

ABSTRACT

This study exposes the friendship between Dr. Marañón and the distinguished academic Sainz Rodríguez, which began in 1924 through correspondence, interrupted by opposing political views and beginning of telephone conversations. However, it's increased from 1955 on by exchanging intellectual interests, and finally ends with the death of Marañón in the spring of 1960.

KEY WORDS: Correspondence; Republic; Monarchy; Sainz Rodríguez;

Gregorio Marañón. 


\title{
CORRESPONDENCIA PEDRO SAINZ RODRÍGUEZ Y GREGORIO MARAÑÓN POSADILLO
}

\author{
JULIO ESCRIBANO HERNÁNDEZ
}

Fundación Universitaria Española

DON PEDRO SAINZ RODRÍGUEZ conoció al doctor Marañón en una reunión de la Compañía Hispano-americana de Publicaciones (CIAP), que mantuvo con su director Manuel Ortega. Fue una comida de trabajo en el Lhardy y en ella surgió una amistad, que aumentaría con los años, como se comprueba a través de las cartas que se guardan en sus archivos. Para Sainz Rodríguez, Marañón «era una persona afable, simpática», que causaba una serena seguridad como hombre objetivo y clarividente.

En los años veinte ambos cuestionaron la política de Primo de Rivera enfrentándose a la Dictadura, aun formando parte de la Asamblea Nacional el profesor de la Universidad Central de la calle ancha de san Bernardo. En la historia de la Dictadura figuran como adversarios entre otros, Marañón, que estuvo un mes confinado en la madrileña cárcel Modelo tras ser multado con cien mil pesetas, Sainz Rodríguez que dejó la Asamblea Nacional, el conde de Romanones, los generales Aguilera y Weyler...

Con la «dictablanda» de Dámaso Berenguer se preparó la segunda República y en este periodo -comenta Sainz Rodríguez- «Marañón 
afiliándose a la Agrupación al Servicio de la República, y yo, conocedor de los verdaderos propósitos de Alfonso XIII, militando en el campo monárquico, nos distanciamos automáticamente. Pero nuestra amistad personal era tan efectiva que la única manera de salvarla era vernos poco. Saludarnos cuando nos encontrábamos y no hablar de cosas que podían envenenar nuestras relaciones». A pesar de todo, Marañón le comentaba al amigo la intimidad de su familia con familiares de Menéndez Pelayo, mostraba una gran imparcialidad en sus escritos y artículos, incluso en alguno de sus ensayos como Liberalismo y Comunismo, dado a conocer durante la Guerra civil. Su experiencia política como diputado independiente por Zamora lo llevó a no intervenir en el parlamento y algunos enemigos le gastaron una broma publicando un libro, titulado Intervenciones parlamentarias de Don Gregorio Marañón, donde las hojas aparecían en blanco y de vez en cuando eran ilustradas con un «sí» o un «no», porque lo único que hacía era votar con cierta desilusión.

Al terminar la Guerra civil reanudaron su amistad: Marañón regresaba del exilio por haber sido republicano, uno de los padres de la república, y Sainz Rodríguez se desterraba en Lisboa como monárquico por estar en desacuerdo con la actuación de los vencedores en la postguerra y mantener su lealtad a la Monarquía.

Don Gregorio lo visitó varias veces en Lisboa donde conversaron gratamente sobre historia, literatura y mística entre otros temas de la cultura española. Recordaba Sainz Rodríguez que cierto día para darle Marañón una tarjeta con su dirección, sacó la cartera del bolsillo trasero de su pantalón y observó que llevaba cosida a la pestaña del billetero una medallita de la Virgen de la Paloma, de la que era muy devoto. Como otros pensadores tenía un peculiar sentido religioso.

En estas cartas se puede apreciar el exponente de los valores que uno y otro desarrollaron en su vida. Al estudiar Marañón en Tácito la dictadura de Franco, confesaba en una carta a Menéndez Pidal: 
«No tenemos derecho a quejarnos de ella, pues la hemos hecho necesaria por nuestra ayuda estúpida a la barbarie roja». Su talante era conciliador, reconocido por los intelectuales del exilio. Azorín proponía a Franco, en una carta fechada en París el 21 de enero de 1939, celebrar una asamblea o conferencia consultiva «cuando llegue el momento» y «propondrá esta conferencia los arbitrios más eficaces y decorosos para la reintegración a la Patria de la intelectualidad ausente. [...] Y la Asamblea podría presidirla hombre de prestigio universal, respetado por todos y tan eminente en ecuanimidad y tacto como el Dr. D. Gregorio Marañón».

[Carta mecanografiada]

[Membrete] ATENEO DE MADRID. SECRETARÍA

[Madrid, 3 de octubre de 1924]

Sr. D. Pedro Sainz

Mi querido amigo: Esperaba para darle la enhorabuena a leer el discurso; pero no he podido lograr un ejemplar. Se la doy, sin embargo, por el gesto, por lo que han podido decir los periódicos y por lo que me han contado. Con un cordial abrazo de su amigo,

G. Marañón

Serrano, 43

[Carta mecanografiada]

[20 de diciembre de 1924]

Mi querido amigo:

Llego de Bilbao y por los periódicos me entero de su conferencia. No pude llegar a tiempo de oírla y tuve por ello una rabieta. Me parece admirable a través de los extractos etéreos de la Prensa y uno mis aplausos a los del público que le oyó. Muy suyo

G. Marañón

Serrano, 43 
[Carta mecanografiada]

[enero 1925]

Querido amigo: Recibí su conferencia, la leí con gran interés, me gustó muchísimo más que leída en extractos. Le saluda con todo afecto su amigo muy devoto,

G. Marañón

Serrano, 43

[Carta mecanografiada]

Sr. D. Gregorio Marañón.

Mi querido amigo y compañero: Un íntimo amigo de Santander me recomienda la adjunta nota, referente a su hijo, que yo a su vez me tomo la libertad de recomendarlo a V. para que si le es posible haga cuanto pueda en su favor.

$\mathrm{Al}$ interesado lo conozco y me consta es muchacho aplicado y trabajador que se hace acreedor de atenderlo en su petición.

Gracias por cuanto haga en obsequio de mi recomendado y sepa dispensar esta molestia a su $\mathrm{affm}^{\circ}$ amigo y compañero q.e.s.m.

Firma: Pedro Sainz Rodríguez

$25 /$ III/ 1936

Recomendando a D. Ángel García Porrero. Recomendado por D. Miguel Quijano.

[Carta manuscrita]

[Membrete] DR. G. MARAÑÓN

CASTELLANA, 59 DPDO.

Madrid, 6 enero 1955

Exmo. Sr. Don Pedro Sainz Rodríguez

Mi querido amigo: Le escribo ahora con una consulta a su gran autoridad. Dice en su libro que «en las artes plásticas podríamos decir que hay misticismo cuando se deforma la realidad para explicar por este medio algo superior y tras- 


\section{CORRESPONDENCIA PEDRO SAINZ RODRÍGUEZ}

cendente de la realidad misma. En un pintor vemos esto: en El Greco». Me parece esto exactísimo y me ha servido mucho para mis meditaciones, que pronto aparecerán, sobre este pintor. Lo que yo quiero consultar con $\mathrm{Vd}$. es esto: Primero, si no cree Vd. que en el misticismo español pudo haber, como muchos piensan, y yo también, desde mi punto de vista puramente naturalista, una influencia hebrea. En este caso, la interpretación de El Greco es fácil, pues su misticismo oriental, de la isla vuelta al Oriente, como dijo Homero, poblada de israelitas, encajaría bien con el misticismo español. Tal vez el mismo de procedencia israelita, de donde su no aplicado empeño de negarse a declarar, en sus pleitos, de donde venía y por qué había venido a España. Esto explicaría su atracción a Toledo entonces poblada de conversos y de espíritu judío. Pero lo que más me interesa de $\mathrm{Vd}$., si tiene la bondad de decírmelo, es si no cree $\mathrm{Vd}$. que hubo al lado de esta variedad del catolicismo místico otra variedad de catolicismo no místico, el que no buscaría la expresión desfigurada, como El Greco, para expresar sus representaciones divinas sino por el contrario un sentido realista como la mayoría de los pintores e imagineros españoles. Claro es que, en realidad, así fue. Mi duda es si este catolicismo muy religioso, muy ascético, pero no místico, con su Dios y sus ángeles y santos de factura humana, no correspondería al catolicismo de sangre limpia, rigurosamente castellano, sin acento oriental. Hay una porción de datos en los que se puede fundamentar esto. La oposición de los dos catolicismos, oposición naturalmente en cuanto a estas interpretaciones estéticas, se resumiría en la repulsa de Felipe II al Greco que no fue repulsa artística, sino teológica, de que «aquellos santos no inspiraban devoción»; en contraste con la vivísima aceptación que tuvo El Greco desde los primeros momentos en una gran parte del catolicismo español, sobre todo en Toledo. Para los cabildos, curas y monjitas de entonces, El Greco era el que pintaba bien a los santos y su taller se convirtió en una verdadera fábrica de San Franciscos, Vírgenes etc. Cuando todavía los entendidos decían que era un loco.

$\mathrm{Si}$ tiene $\mathrm{Vd}$. unos minutos y me quiere decir su opinión sobre este pequeño problema se lo agradecería mucho. De todos modos, Vd. a través de su libro, es uno de mis guías en este pasatiempo de mis otras ocupaciones.

Un fuerte abrazo de su amigo

[Firma ilegible: Marañón] 
[Carta mecanografiada]

Lisboa, 9 de enero de 1955

\author{
Excmo. Sr. D. Gregorio Marañón \\ Madrid
}

Mi querido amigo: Con mucho gusto contesto a su carta del 6 sobre temas místicos. Ahora le anticipo lo que se me ocurre, sin perjuicio de que continuemos esta conversación epistolar, que tan útil puede ser para mí, por contrastar mis ideas con las de Vd. y con su fina intuición en materia histórica.

Celebro que mi libro juvenil Introducción a la Mística le sea de alguna utilidad. Como todas las obras juveniles, contiene afirmaciones rotundas y osadas, que precisamente por conocer hoy muchísimos más elementos de juicio sobre cada problema no me atrevería a formular en los mismos términos categóricos.

Antes de entrar en el tema místico quiero dejar anticipado que ese libro mío responde a una interpretación de la historia de la literatura y de la psicología de España algo unilateral. En la pág. 291, en la nota 1, verá Vd. cómo ya entonces me apuntaba el escrúpulo de que había otros aspectos de nuestra historia cultural artística y de nuestra psicología que no habían sido suficientemente considerados. El constructor último de toda la teoría a que aludo fue Don Marcelino y desde entonces pasó por un dogma el realismo del arte español, el realismo de nuestra literatura, la supervivencia medieval, el predominio ascético sobre el místico, etc., etc. Estudios posteriores han descubierto nuevos elementos, que a mi juicio demuestran que, si bien todas esas afirmaciones son substancialmente verdaderas y esas características acaso predominen en nuestra personalidad histórica, hay otras que vienen a complicar el problema mostrando un arte y una psicología nacional más compleja. Precisamente creo que el análisis de este problema nos esclarece algo muy interesante sobre la personalidad crítica y la formación mental de Menéndez Pelayo. Él, que tuvo aquella objetividad para apreciar y gustar las más diferentes escuelas y tendencias artísticas, en realidad tenía en 


\section{CORRESPONDENCIA PEDRO SAINZ RODRÍGUEZ}

su formación y en su sensibilidad literaria una especie de falla, la que le hacía antipatizar con el arte escurialense; la que le hizo no entender la literatura de Góngora, y la que le hizo que no acertase a interpretar todo el movimiento barroco como una sensibilidad nueva y sí, exclusivamente, como un movimiento de decadencia.

No obstante, sus bellas páginas sobre la poesía mística, la literatura espiritual y ascética no fue nunca su flaco y lo prueba lo poco que escribió sobre ella. Don Marcelino era un humanista cristiano y muchas veces su formación clásica choca con concepciones que su mentalidad católica tenía que aceptar. Así, por ejemplo, su doctrina crítica del arte por el arte era algo incompatible con una estructuración escolástica sobre la moral en el arte. Otra de las tragedias íntimas de la mentalidad de Don Marcelino era el choque evidente de la moral pagana con la moral cristiana; aquella, llena de la belleza que él amaba, y esta, representativa de la verdad en que creía. Hecha esta salvedad, para explicar algunos exclusivismos de mi libro, como yo entonces inspirado y formado en la escuela de Don Marcelino, paso al tema concreto que me plantea su carta.

Esa afirmación que $\mathrm{Vd}$. cita sobre la manera de reflejarse lo místico en el arte, continúo creyéndola exacta, como Vd. Quizá sea exagerado decir que el único pintor que supo expresar lo místico fuese El Greco, aunque es innegable que él lo hizo de una manera sistemática por esa deformación de la realidad exterior. Acaso, otros pintores, sin acentuar esa manera, o por otros procedimientos, lograron algo similar. Estoy pensando en el San Antonio, de Murillo, y creo que un repaso por nuestra pintura religiosa nos daría algún otro caso. Lo que a mí me sulfuraba y me sigue irritando era el tópico de los catálogos de museos cuando ponían «asunto místico» y el tal asunto consistía en una buena mujer hilando al lado de un carpintero y con un niño al pie jugando con un perrito. Es decir, una sagrada familia, que tenía de místico el representar a la Virgen, a san José y al Niño, por decisión libérrima del pintor, pero que, como arte, era un cuadro realista de asunto familiar y doméstico, pero nada místico.

Para no caer en digresiones le voy a enumerar a Vd. unas cuantas conclusiones que reflejan mi opinión sobre la evolución de nuestro misticismo y que responden a dos preguntas concretas que Vd. me hace: a) Si ha habi- 
do una influencia hebrea en el misticismo español; b) Si las dos facetas, la típicamente mística y la predominantemente ascética y realista, pueden adscribirse respectivamente al grupo racial de los cristianos nuevos o de origen judío y al núcleo de los cristianos viejos de sangre limpia. Ahí van mis conclusiones.

$1^{\text {a }}$.- El misticismo español del XVI recoge una serie de elementos e influencias y nace inmediatamente engendrado por la siembra de las ideas místicas de origen libresco que produce la que pudiéramos llamar siembra cisneriana de publicaciones y la reforma de las costumbres monásticas y sociales llevada a cabo por el Cardenal. La literatura mística se desarrolló en un caldo de cultivo popular y recibió su savia del movimiento espiritual iluminista o alumbrado, que adquirió un desarrollo enorme en España durante los veinticinco primeros años del siglo XVI. Este movimiento iluminístico es, en cierta manera, autóctono y desde luego ajeno en absoluto en su primera época al movimiento luterano, al cual es, en algunos casos, anterior. Creo que las raíces de este movimiento hay que buscarlas en la espiritualidad franciscana medieval. La lucha interior de la Orden de San Francisco, entre espirituales y conventuales, que produjo una verdadera insurrección y que dio lugar a los movimientos profetistas, como el joaquinismo, y a una verdadera plaga de espirituales que se extendieron por Europa, visionarios, bellinos y fraticheli, llenos de exaltación espiritual y con un espíritu de rebeldía anarquizante contra toda autoridad eclesiástica. Aquí está la raíz de nuestro iluminismo. Este movimiento espiritual ha sido, en parte, estudiado en su expansión levantina y catalana en un libro que seguramente le ha de interesar, si no lo ha leído ya, del P. Pou y Martí Visionarios, beguinos y fraticelos catalanes (siglos XIII-XV), Vich, Editorial Seráfica, 1930. También los estudios realizados en torno a la personalidad de Arnaldo de Vilanova han aportado elementos muy interesantes para el estudio de este movimiento espiritual.

En Castilla está mucho menos estudiado, pero no cabe duda que también se extendió hasta aquí y el hecho mismo de la aparición de los alumbrados es una prueba a posteriori.

$2^{\mathrm{a}}$.- En la masa de los alumbrados predominaba el elemento de judíos conversos. María Cazalla y su hermano el Obispo Juan de Cazalla, Fray 
Francisco Ortiz, Luis de Beteta, Bernardino de Tovar, los Vergara, Isabel de la Cruz y Alcaraz eran conversos o procedentes de familias de conversos. Además, el elemento aristocrático que se preocupaba por la reforma de la vida religiosa en el país, como el Marqués de Villena y su esposa, los Mendoza, Duques del Infantado y Don Fadrique Enríquez, Almirante de Castilla, y otros, eran profundamente influidos y hábilmente dirigidos por mayordomos, clase social en la que predominaban los conversos que tuvieron habilidad para apoderarse de estos puestos de mayordomo, administrador o secretario de las casas de la nobleza. Y esto sin contar el elemento racial judío, que sin caer en las exageraciones del célebre Tizón de la Nobleza es evidente que existía en algunos linajes. Aparte de este elemento popular alumbrado, muchos de los escritores que producen la primera gran cosecha de nuestra literatura mística, que yo sitúo entre el año 1520 y el año 1559, en que aparece el Índice de Valdés, eran también de origen judío. Una de las grandes figuras de este movimiento, el Beato Ávila, era de raza judía, y entre sus discípulos predomina este elemento, que por serlo encontraban dificultades para entrar en algunas Órdenes, siendo san Ignacio el que les invitaba a ir a Roma, pues él nunca participó del prejuicio racial. Creo, pues, evidente que sí; que en la mística española existe un elemento racial judío. Claro es que dejo aparte la fuente primitiva escrituraria y apostólica notoria y conocidamente judía y que tuvo su influencia no en la nuestra sino en la mística universal.

$3^{\mathrm{a}}$.- Pueden encontrarse ciertas notas comunes doctrinales en autores cuya personalidad judía nos es conocida, pero esto no es muy seguro, pues dentro del elemento judío hay posiciones doctrinales contradictorias. Creo, pues, muy difícil el poder determinar el que la escuela que pudiéramos llamar mística sea exclusivamente judía y mucho más difícil aún el determinar que la que hemos llamado puramente ascética sea exclusivamente cristiana vieja. La reacción contra el misticismo exagerado, en su tendencia iluminista y por su peligro de contagio con el luteranismo, se produjo muy rápidamente, desde 1525, y culminó con la implacable persecución a la literatura mística, que representa el índice inquisitorial de Valdés (1559) dirigido e inspirado doctrinalmente por la alta mentalidad de Melchor Cano. Precisamente esta personalidad puede servirnos de ejemplo para demos- 
trar las contradicciones y las posturas diversas y heterogéneas que tomaba el elemento judío, pues según parece Cano era de familia judía. Vitoria, según acabo de descubrir, también lo era, y salvo sus aficiones humanísticas no tiene doctrinalmente grandes vinculaciones con el movimiento místico. Creo que para puntualizar este problema lo mejor será el que yo le prepare a Vd. una nota de autores típicamente místicos o de mentalidad iluminada cuyo origen judío se conozca; otros con las mismas características y cuyo carácter de cristiano viejo nos conste, y viceversa, autores de la reacción anti-mística cuyo origen judío nos conste. Así, sobre casos concretos, se podrá ver la realidad de las posiciones contradictorias del grupo judaizante y cómo estas posiciones doctrinales es muy difícil vincularlas a las características raciales, aunque se note el predominio de algunas en el grupo cuyo origen judío nos consta.

Hay que tener presente que los marranos, usando el nombre con que se les designaba, precisamente por sentirse socialmente perseguidos, eran doctrinalmente partidarios de la postura libertaria en materia religiosa, pero no lo eran ellos exclusivamente. También sabemos que en la historia de pensamiento y de la cultura judía existe el elemento místico, mesiánico y profético, pero al lado de él hay pensadores judíos que pueden ser considerados como los padres del racionalismo moderno y por tanto profundamente anti-místicos.

Mucho me agradará que continuemos hablando de estas cosas y que me comunique Vd. sus puntos de vista y cuantas pegas y objeciones se le ocurran al leer esta deslavazada exposición, pues nada me será más útil para yo mismo fijar y aclarar mis ideas.

Creo que habrá Vd. visto el libro de Américo Castro, donde se tocan estos temas. En él hay cosas a mi juicio interesantes, pero está escrito con un apasionamiento grande que le priva de objetividad histórica, sacando de quicio algunos argumentos que basa en pequeñas cosas y a veces desconociendo hechos importantes que podrían ser alegados a favor de sus tesis.

Sin más por hoy le envía un afectuoso abrazo su admirador y amigo

Firma: Pedro Sainz Rodríguez 
[Carta manuscrita]

[Membrete] DR. G. MARAÑÓN

CASTELLANA, 59 DPDO.

3 febrero 1955

Sr. D. Pedro Sainz Rodríguez

Mi querido amigo: No sabe $\mathrm{Vd}$. cuanto le agradecí su rápida y eficaz carta, llena de datos interesantísimos, como venidos de tan alta autoridad. Los estoy aprovechando al máximo para mi librillo. Con el permiso de Vd. le comunicaré mis dudas en adelante. En efecto, he leído el libro de Américo Castro. Me parece, como a Vd. muy faccioso. En efecto, lo que más me interesa del problema es el posible origen israelita de una parte de las manifestaciones del misticismo español. Cada día me parece más cierto que el éxito de El Greco, en su tiempo, se basaba en la afección con que vieron su obra los católicos de sangre hebrea. Cuando se ha publicado mi conferencia que tocaba este punto, en los Anales de la Universidad Mediterránea (me enviarán ahora apartes y le enviaré uno) he recibido enseguida cartas de varios hebreos entre ellos de la hija de Max Nordau, acogiendo con entusiasmo la interpretación.

Un gran abrazo de su devoto amigo

[Firma ilegible: Marañón]

[Carta mecanografiada]

Lisboa, 27 de febrero de 1955

\section{Excmo. Sr. D. Gregorio Marañón}

Mi querido amigo: Acuso recibo de su carta del 3 del corriente para comunicarle que desde luego puede $\mathrm{Vd}$., con toda libertad, proponerme cuántas dudas o consultas se le ocurran y en la que ojalá pueda serle útil. Sin duda, en estas consultas el más beneficiado he de ser yo, pues me obligará Vd. a fijar mis ideas sobre puntos interesantes de una materia que tengo en estudio.

Es evidente que si no podemos afirmar que un tipo determinado de espiritualidad esté adscrito a los que podemos llamar cristianos viejos, no lo es 
menos que durante un determinado periodo de la evolución de nuestro misticismo y en un determinado sector de la espiritualidad predomine a los conversos.

En mi carta anterior le hablaba yo a Vd. del caldo de cultivo iluminista o alumbrado en que se desarrolló el primer periodo del misticismo español hasta la reacción anti-mística que señala el Índice de Valdés de 1559. Durante toda esa época que podemos situar de 1520 a 1559 , los ascetas y místicos españoles procuran una renovación de la espiritualidad, una verdadera reforma en la que dé frutos la reforma de las costumbres hecha por Cisneros y la siembra de traducciones y ediciones místicas llevadas a cabo por el cardenal franciscano. En 1525 se realiza la primera persecución contra los alumbrados y entonces los más letrados de ellos procuran guarecerse en el ambiente erasmista, que durante muchos años fue protegido en las esferas oficiales del Estado y de la Iglesia. Quizás Bataillon no se ha dado cuenta exacta de que lo que él llama eclosión o explosión erasmista fue en realidad una maniobra de los alumbrados para protegerse con la gran autoridad europea del humanista holandés, con el que simpatizaban grandes jerarcas de la Iglesia y que el propio Emperador protegía. Este fenómeno me recuerda algo a lo que ahora está pasando con el protestantismo en España. Yo creo que mucho elemento, que para abreviar llamamos rojo, discrepante del régimen actual, se disfraza de protestantismo porque en esa trinchera encuentra una protección internacional que le permite defender su independencia política. No puedo creer en un renacimiento protestante de tipo religioso, y sí en esta ficción que sería muy similar a la de los alumbrados, cobijándose en el erasmismo.

Todo este periodo se caracteriza porque todavía no existen las definiciones dogmáticas de Trento y así vemos muchos autores estar haciendo equilibrios sobre doctrinas discutibles en espera de una resolución. Ejemplo de esto es lo que le pasó al P. Ávila con su Audi Filia. La primera edición fue condenada por la Inquisición y la segunda fue corregida por el propio Ávila. El cotejo de las dos ediciones nos muestra cuales eran los temas resbaladizos, por ejemplo, el de la justificación, punto central de la doctrina protestante. La idea de que Cristo con su pasión nos redimió con el pecado, que es la doctrina que llaman el beneficio de Cristo, y cuyo expositor más cons- 


\section{CORRESPONDENCIA PEDRO SAINZ RODRÍGUEZ}

picuo entre nosotros es Juan de Valdés, traía como consecuencia aparejado el error protestante de la ineficacia de las obras para la salvación. Pues bien; todo este periodo de nuestra espiritualidad, que acabo de indicar, está lleno de influencia de los conversos. Juan de Ávila lo era; la Compañía de Jesús, recién fundada, simpatizaba con los conversos y nunca se prestó a exigir la limpieza de sangre, siendo esta la causa de todas sus luchas con el Cardenal Siliceo, que con su Estatuto para la Iglesia de Toledo señala un momento crítico en la historia social y espiritual de España. El segundo General de la Compañía, Laínez, era notoriamente de familia de conversos; en el grupo de discípulos del Beato Ávila, que se esparcieron por toda Andalucía, se pueden señalar con absoluta certeza bastantes conversos. El gran predicador Constantino de la Fuente, que murió en las cárceles consistoriales, también era de raza de conversos. Todo este género de espiritualidad era apoyado y defendido por un grupo de dominicos entre los cuales está Fray Luis de Granada y un dominico muy poco conocido llamado Fray Domingo de Baltanás, que fue preso por la Inquisición, y que en un librito suyo muy raro del que poseo fotocopia, publicó una apología sobre la cuestión de los linajes atacando el tema de la limpieza y señalando muchísimos de raza judía entre los personajes más conspicuos de su tiempo. Allí se descubre que el gran Francisco de Vitoria era también de raza judía.

Este grupo de dominicos, al cual pertenece el maestro Salucio; Meneses, el autor de La Luz del Alma (libro citado por Cervantes), era en cierto modo capitaneado por Carranza y es un choque de criterios sobre cómo se había de hacer la reforma de la Iglesia y de la espiritualidad española lo que provocó la divergencia entre el grupo reaccionario que luego había de triunfar en Trento, cuya cabeza doctrinal es Melchor Cano, y la tendencia vencida con el hundimiento de Carranza y con las persecuciones del Índice inquisitorial.

En Portugal se refugió el P. Granada y apoyándose en el Cardenal Don Enrique, en Fray Bartolomé de los Mártires, Arzobispo de Braga, y en el Obispo de Évora, Don Teotonio de Pererira, editor de las obras de santa Teresa y protector y amigo de la santa, procuró salvar con su influencia el tipo de espiritualidad que era perseguido en España. Así se da el caso de que en alguno de los libros se imprime a continuación la Confesión de un pecador 
de Constantino de la Fuente, el canónigo muerto en las cárceles inquisitoriales de Granada y quemado en efigie. Un librito muy interesante y desconocido, titulado Perla preciosísima, incluido en el Índice de Valdés, fue reimpreso en Portugal por el P. Granada.

Este tipo de espiritualidad, que era una especie de reforma autóctona, pre-tridentina de la espiritualidad española, se malogró, y después de la implantación de los decretos del Concilio de Trento el misticismo español va decayendo y derivando hacia un carácter puramente doctrinal sin manifestaciones de mística experimental, aunque todavía el antiguo fermento iluminista levantó la cabeza en la segunda mitad del XVI y en la primera del XVII.

Pongo punto final a esta disertación un poco deslavazada, pero que acaso le sirva a Vd. para formarse un ligero esquema de las corrientes de espiritualidad en las que puede Vd. insertar las hipótesis referentes a su trabajo.

Mucho le agradeceré que me envíe esa separata que me ofrece, pues con el texto a la vista quizás se me ocurra alguna sugestión útil.

Agradeciéndole sus buenas ausencias sobre mi biblioteca y mis trabajos, le envía un cariñoso saludo su verdadero amigo

Firma: Pedro Sainz Rodríguez

[Carta manuscrita]

[Membrete] DR. G. MARAÑÓN

CASTELLANA, 59 DPDO.

Abril 1955

\section{A Sr. Dr. Pedro Sainz Rodríguez}

Mi querido amigo: Con gran retraso le envío mi gratitud por su carta y por el opúsculo sobre la formación de los jesuitas, que me ha sido tan grato como útil. Tengo estos meses interrumpido mi trabajo por el aluvión de enfermos y por el enorme quehacer en la Universidad. Pero espero reanudarlo ahora tras los exámenes. 


\section{CORRESPONDENCIA PEDRO SAINZ RODRÍGUEZ}

Confiando en su bondad y generosidad, le mandaré, entonces, alguna consulta más.

Recordando siempre mi visita a su casa y archivo, le envía un abrazo su buen amigo

[Firma ilegible: Marañón]

[Carta mecanografiada]

Lisboa, 27 de noviembre de 1955

\section{Sr. D. Gregorio Marañón}

Mi querido amigo: He recibido su ANTONIO PÉREZ, con la bondadosa dedicatoria que ha tenido $\mathrm{Vd}$. a bien ofrecerme. Me lo he leído de un tirón robando horas al sueño. Puede Vd. estar contento, pues es un libro magnífico. Aparte de la reconstrucción histórico-biográfica del personaje central, exacta y sugestiva, nos ofrece este libro una de las calas más hondas y extensas en la historia de todo ese periodo. Al pasar se hacen semblanzas de tantos personajes que cuando uno termina la lectura parece que ha asistido a la resurrección de aquella sociedad.

Después de los mares de tinta que se han escrito sobre Felipe II, parecía difícil decir algo nuevo, y, sin embargo, creo que Vd., además de haber resuelto definitivamente el problema del asesinato de Escobedo, ha trazado en torno de este suceso una sugestiva vivisección psicológica de Felipe II, que será muy difícil de modificar en lo sustancial y que aclara con objetividad y sentido histórico a la vez el misterio de esta complicada personalidad histórica.

Me han divertido también mucho las alusiones, goteadas a lo largo de la obra, sobre la España de nuestro tiempo.

¿No le ha interesado a Vd. nunca examinar cómo han sido interpretados los sucesos y los personajes que forman la trama de su libro en la literatura folletinesca y en los novelones históricos del siglo XIV? Yo tengo sobre eso una enorme cantidad de notas, pues en un libro que tengo elaborado, aunque no escrito sobre la historia de las interpretaciones de la Historia de 
España, dedico un largo capítulo a Felipe II y con este motivo he recogido muchos datos sobre el reflejo de su personalidad en la literatura. En un novelón de Ortega y Frías, titulado El diablo en Palacio, el personaje central es ese Marqués de Poza, de quien habla Vd. en una nota, y no me imagino de dónde sacaría el autor esa novela (Ortega y Frías) los datos para elaborar su trama, en que parece olfatear algo de lo que fue la realidad.

Algunas de las observaciones que hace Vd. sobre la personalidad de Felipe II (timidez, indecisión, lentitud y alguna otra) me han recordado las características de cierto personaje histórico también ya, que tiene $\mathrm{Vd}$. ahí.

Un afectuoso abrazo de su agradecido amigo

Firma: Pedro Sainz Rodríguez

[Carta manuscrita]

[Membrete] DR. G. MARAÑÓN

CASTELLANA, 59 DPDO.

\section{Al Sr. Dr. P. Sainz Rodríguez}

Querido amigo: Por correo aparte le envío su introducción a la Antología. La he leído y releído. Me parece admirable. Seguramente, el libro será, más que un gran éxito, un acontecimiento en la vida española. Digo una gran verdad. España necesita saber su religión; quizá y sin quizá, antes que ninguna otra cosa. La vida espiritual, en el alto sentido científico, la conocen unos pocos. Usted va a realizar la gran obra de que la conozcan muchos y, sobre todo, de que tenga un «estado científico», muy encendido de espiritualidad, pero en el plano de la doctrina, sin otra pasión que la suya propia y no en la de la calle. Otra vez lo diré más claramente. Ahora le escribo después de una jornada abrumadora de trabajo; y de emociones; porque usando del ya lugar común «me duele España», con dolor agudo. Pero veo claro la trascendencia de su obra y el designio providencial que le ha llevado a ella y la ha hecho posible.

Un gran abrazo de su amigo

G. Marañón 


\section{CORRESPONDENCIA PEDRO SAINZ RODRÍGUEZ}

[Carta manuscrita]

Madrid, 5 de mayo de 1956

Castellana, 63

\section{Sr. D. Pedro Sainz Rodríguez}

Mi querido amigo: Hace tiempo que quiero escribirle y el insano tráfago de esta vida madrileña me ha hecho demorarlo un día y otro. Quería decirle que al fin he escrito mi libro sobre El Greco. Un par de sus capítulos me servirán para el ingreso en la Academia de Bellas Artes que será en este mes. El tomo, con no muy extenso texto y muchas estampas aparecerá, creo, antes del verano. He utilizado mucho los datos que tuvo $\mathrm{Vd}$. la bondad de proporcionarme. Veremos si, estos y los otros, los he aprovechado con tacto.

Apenas pude ver al Sr. Donoso durante el Congreso, pues apenas he podido asistir a él, fuera de la sesión inaugural en la que hice el discurso. Y la de clausura, que, por cierto, fue estupenda, pero en la que había demasiada gente. He escrito a Donoso poniéndome a su disposición.

¡Pienso cómo estarán los reyes! Todo el mundo ha tenido una verdadera pesadumbre y creo que les acompaña el sentimiento unánime del país.

Con un fuerte abrazo sabe es su buen amigo

G. Marañón

[Carta manuscrita]

[Membrete] DR. G. MARAÑón

CAstellana, 63

Madrid, 21 de julio de 1956

\section{Sr. D. P. Sainz Rodríguez}

Mi querido amigo: He dedicado mi domingo de Toledo a leer su estupendo ensayo sobre Menéndez Pelayo, en la edición de Aguado. Es una muestra, óptima, de su sabiduría lograda, equilibrada y, a la vez, vivaz y 


\section{JULIO ESCRIBANO HERNÁNDEZ}

juvenil. Gran alegría me ha producido porque las tonterías que se han dicho sobre don Marcelino han creado (lo sé porque lo recojo en la Universidad) un desvío de la juventud hacia el gran maestro. El ensayo de Vd. es digno de él, de lo que era, abierto, generoso, con limitada capacidad de adaptación a todo lo nuevo y la vida es nueva cada día. iY estos señores, pretenden detenerle en Los heterodoxos, y en la Ciencia Española, o, más aún, en las primeras ediciones de ambas obras!

El libro de Dámaso está bien, tal vez un poco incisivo, aunque siempre exacto. Lo incisivo es fruto de la reacción ante las sandeces, que obligan a afilar los dientes. José $\mathrm{M}^{\mathrm{a}}$ Cossío hará una cosa buena en la Inauguración del Curso de Santander.

Yo he terminado mi libro sobre Toledo y El Greco. Está en la imprenta, en segundas pruebas. Ya se lo enviaré. Le cito mucho y con toda admiración.

Un cordial saludo de su amigo,

G. Marañón

Gracias por las citas en su Ensayo.

[Carta manuscrita]

[Membrete] DR. G. MARAÑÓN

CAstellana, 63

Madrid, 23 de setiembre de 1956

\section{Sr. D. Pedro Sainz Rodríguez}

Mi querido amigo: He recibido el librito, corto por su tamaño, grande por su contenido. Lo he releído y me parece aún mejor que en la primera lectura.

He hablado mucho de él y espero que tendrá la trascendencia que merece.

Todo lo referente a don Marcelino requiere una crónica detallada. Algún día se hará.

Sabe cuánto le quiere su buen amigo

G. Marañón 


\section{CORRESPONDENCIA PEDRO SAINZ RODRÍGUEZ}

[Carta manuscrita]

[Membrete] DR. G. MARAÑón

CASTELlana, 63

Madrid, 23 de enero de 1957

Sr. D. Pedro Sainz Rodríguez

Mi querido amigo: Mil gracias por el San Ignacio y Erasmo, imuy interesante! Me lo entregó ayer Pelayo y esta noche misma, lo he leído. iCuántas cosas sabe $\mathrm{Vd}$.!

Iré pronto a Lisboa y le llevaré mi libro El Greco y Toledo.

Con un gran abrazo de su amigo,

G. Marañón

1957- febrero

[Telegrama mecanografiado]

E L T $23-X-57$

Gregorio Marañón-Castellana 66- Madrid

Hago votos por un pronto y total restablecimiento cariñoso abrazo

Pedro S. Rodríguez. R. Al. Herculano, 3-Lxa

Firma: Pedro Sainz Rodríguez

[Carta mecanografiada]

Lisboa, 30 de abril de 1957

Excmo. Sr. D. Gregorio Marañón

Mi querido amigo: Estoy en grave deuda con Vd., no habiendo contestado a la bondadosa carta en que $\mathrm{Vd}$. me daba su juicio sobre la parte del prólogo de mi Antología, que le di a leer. Tal juicio, procediendo de un hombre del criterio de $\mathrm{Vd}$. y con su espíritu de justicia, universalmente reconocido, bastaría para hacerme sentir la responsabilidad en que yo podría incurrir si 
por pereza dejase de terminar mi trabajo. Las palabras de Vd. serán para mí como una inyección de fe, de optimismo y de energía. Que Dios se las pague como yo se las agradezco desde lo más profundo de mi espíritu.

No quería contestarle sin haber terminado la lectura de su Greco y Toledo, que, por diversos azares y ocupaciones enojosas tuve que interrumpir. Es un libro bellísimo y lleno de encanto, en el que se aprende sobre El Greco mucho más que en los críticos especialistas de pintura, y en que se entiende con un ejemplo histórico tan evidente cuál puede ser la influenza del medio ambiente en la creación de la obra de arte y en la formación del genio artístico. Este ejemplo vale por todas las teorías que sobre el asunto se han elaborado. Toledo y El Greco quedarán para la posteridad como algo indisolublemente unido gracias a su labor investigadora y al encanto de la bella prosa de su libro. Es algo así como la simbiosis realizada entre Luis Vives y la ciudad de Brujas, de la cual se ven muestras patentes en el bello libro de Rodembach Brujas la muerta. No ha hecho nada de más Toledo con honrar lo mucho que ha hecho Vd. para resucitarlo históricamente y hacerlo visible a la sensibilidad moderna.

Espero que en breve saldrá mi Antología y tendré el gusto de mandarle a Vd. con anterioridad, la segunda parte del prólogo.

Un cariñoso abrazo de su verdadero y agradecido amigo

Firma: Pedro Sainz Rodríguez

[Carta manuscrita]

[Membrete] DR. G. MARAÑóN

CASTELlana, 63

19 marzo 1960

Sr. Don Pedro Sainz Rodríguez

Mi querido amigo: No sé si vuelvo a escribirle de nuevo o si le escribo por primera vez sobre los admirables Camino del Cielo y de la Maldad y Ceguedad del Mundo y Avisos para los predicadores del Santo Evangelio.

El vacar que me permiten estos días, en que he estado indispuesto, me dejan entretenerme en estos gustosísimos trabajos. He tenido verdadera alegría leyéndolos y revisándolos. 


\section{CORRESPONDENCIA PEDRO SAINZ RODRÍGUEZ}

Desearía hablarle de otras muchas cosas, unas ciertas y otras inciertas. Mi hijo le habló de varias de ellas. Yo ando fluctuando. Y es natural que así estemos todos.

Un gran abrazo de su buen amigo

G. Marañón

[Carta mecanografiada]

Lisboa, 21 de marzo de 1960

\section{Excmo. Sr. D. Gregorio Marañón}

Mi querido amigo: Su carta hablándome de los primeros volúmenes de mi colección «Espirituales españoles» me ha causado gran alegría porque me demuestra que su indisposición, de la que tenía noticia, no ha sido cosa de cuidado a Dios gracias. Me encanta que haya V. encontrado interesantes los dos primeros volúmenes de mi serie. Acaba de salir el tercero que V. recibirá, que está formado por escritos del mercedario Fr. Juan Falcón, figura importante y olvidada de nuestra espiritualidad no obstante haber tenido extraordinaria influencia en Europa, especialmente en Italia. Es el primer volumen de este año 1960 en el que esperamos publicar once más, que ya están preparados.

Si V. dice que desearía hablarme icalcule lo que yo daría por un cambio de impresiones con V.! Las cosas siguen en el mismo pie que cuando hablé con su hijo a quien no veía desde tantos años y que me causó una magnífica impresión.

Deseándole de todo corazón salud, le envía un afectuoso abrazo su viejo amigo

Firma: Pedro Sainz Rodríguez

[Telegrama manuscrito]

27 de marzo de 1960 
Gregorio Marañón Moya

Serrano 49. Madrid.

Muy sincero emocionado pésame ruego transmita familia cariñoso abrazo. Pedro Sainz Rodríguez.

Pedro S. Rodríguez. Alexandre Herculano 3. $2^{\circ} \mathrm{d}^{\mathrm{o}}$. Lisboa.

[Carta mecanografiada]

[Membrete] GREGORIO MARAÑÓN MOYA

ABOGADO

Madrid, 11 de abril de 1960

Serrano, 49

Excmo. Sr. D. Pedro Sainz Rodríguez

Lisboa

Querido y admirado amigo; agradecí, de todo corazón, su sentido pésame por el fallecimiento de mi padre (q.e.p.d.).

Se lo leí a mi madre y demás familia. En estas horas de profundo dolor para nosotros, el recuerdo de los buenos amigos es nuestro mejor consuelo.

La adhesión que a su memoria ha demostrado España entera, es realmente algo difícil de superar.

A pesar de ello, a toda esta triste familia le es muy duro conllevar el vacío inmenso.

Mi padre sentía por Vd. una sincera amistad y una auténtica y profunda estimación por su persona y por su obra. Desde siempre. Lo sabe Vd. muy bien.

Dos o tres días antes de su muerte, despachando con él una tarde, me leyó la última carta de Vd. y me encargó que le leyera -él ya no podía- la Semblanza de San Alonso Rodríguez tan bondadosamente dedicada por Vd.

Le envía un abrazo su buen amigo,

Gregorio Marañón 


\section{CORRESPONDENCIA PEDRO SAINZ RODRÍGUEZ}

\section{BIBLIOGRAFÍA}

AA.VV. (1989): Historia de España. España actual. La Guerra Civil (19361939), Vol. 13, 1, Madrid, Gredos.

AZAÑa DiAZ, Manuel (1997): Diarios, 1932-1933: «Los cuadernos robados», intro. Santos Juliá, Barcelona, Crítica.

(1978) Memorias políticas. I (1931-1933), Barcelona, Crítica. (1966): Obras Completas, México, Oasis.

EsCRIBANO HernánDeZ, Julio (1998): Pedro Sainz Rodríguez, de la Monarquía a la República, Madrid, Fundación Universitaria Española.

MARÍAS, Julián (1966): Al margen de estos clásicos. Autores españoles del siglo XX, Madrid, Afrodisio Aguado.

MOA, Pío (2001): El derrumbe de la segunda república y la guerra civil, Madrid, Encuentro.

(2000): Los personajes de la República vistos por ellos mismos, Madrid, Encuentro.

(1999): Los orígenes de la Guerra Civil Española, Madrid, Encuentro.

PALACiOS, Jesús (2005): Las cartas de Franco. La correspondencia desconocida que marcó el destino de España, pról. Stanley G. Payne, Madrid, La esfera de los libros.

RIVAS, Natalio (1987): «Cincuenta cartas a Marañón», ABC literario, (18VII), 45-60.

SAinz Rodríguez, Pedro (1988): Semblanzas, pról. José María de Areilza y epíl. Luis María Ansón, Barcelona, Planeta. (1986): Visión de España, Madrid, Fundación Cánovas del Castillo. (1978): Testimonio y Recuerdos, Barcelona, Planeta.

TUSELL, Xavier (1977): La oposición democrática al franquismo. 1939-1962, Barcelona, Planeta. 